\title{
TESIS DIDACTICAS
}

"ANALISIS DE LAS CONCEPCIONES DEL ESTADO GASEOSO Y DE PRESION QUE TIENEN LOS NIÑOS DE 11 A 13 AÑOS, Y PROPUESTA DE ESTRATEGIAS PEDAGOGICAS PARA FACILITAR LA EVOLUCION)

Tesis de Doctorado, presentada por Geneviève Séré en la Universidad Pierre y Marie Curie (París 6) el 24 de Abril de 1985

Desde septiembre de 1977 se empiezan a estudiar las ciencias físicas en Francia a la edad de 11 años, en $6^{\circ}$ curso. Durante los dos primeros antos $\left(6^{\circ}\right.$ y $\left.5^{\circ}\right)$ los alumnos reciben una enseftanza sobre los diferentes estados de la materia. Entre los tres estados de la materia, el gaseoso es objeto de un estudio especifico que encuentra su aplicación en biología y en química ya que las reacciones químicas ponen a menudo los gases en juego.

El objeto de este trabajo es Ia descripción y el estudio de las concepciones de los alumnos sobre el estado gaseoso, tal como es estudiado y presentado en los dos primeros años de estudio de la física.

\section{Primera parte}

En la primera parte, se estudia y expljcita el programa escolar francés. En particular se estudian las experiencias propuestas clásicamente a los alumnos para estudiar la presión. Se muestra que este programa supone ta articulación de las nociones de movimiento, equilibrio mecánico, equilibrio térmico, fuerza y presión. Se busca en consecuencia precisar cómo intervienen estos conceptos. Se comparan las dos descripciones que da la física de los gases: un gas puede ser considerado como un medio continuo cuyos constituyentes, las partículas gaseosas, son inmoviles, o al contrario, como un conjunto discontinuo de partfculas en movimiento en el marco de la teoría cinética. Cada una de estas descripciones tiene un dominio de aplicación propio. Se recuerda lo que es un gas en movimiento (régimen tran- sitorio, permanente) o en equilibrio, después se estudian las fuerzas que se ejercen, sobre un gas así como los diferentes significados del término presión (cinético, estático, dinámico, local, global) precisando cuál interviene en cada una de las experiencias del programa.

Según las situaciones parece que la presión de la que hablan los alumnos se aproxima a una u otra de las acepciones del término. Su multiplicidad debe ser tenida en cuenta para comprender las concepciones de los alumnos.

\section{Segunda parte: Problemas y métodos de investigación}

Se precisan aquí los elementos producidos por el alumno que nos interesan. Para estudiarlos utilizarnos Ios siguientes métodos:

\section{- Cuestionarios escritos.}

- Conversaciones individuales con planteamiento experimental.

- Cuestiones acompañando las actividades de clase, propuestas a más de 250 alumnos de $6^{\circ}$ y después en $5^{\circ}$.

- Una observación hecha en una clase, suficientemente larga para seguir la evolución de los alumnos.

- Actividades propuestas a grupos de 2 o 3 alumnos en situación de autonomia con el objeto de establecer un balance de las adquisiciones de los alumnos.

Algunos de estos métodos se llevan a cabo durante el transcurso mismo de la ensenanza mientras que otros no. Sin embargo tienen por objeto destacar las representaciones e interpretaciones de los alumnos en diferentes momentos y condiciones (autonomia/toma de información, experimentación, trabajos escritos etc...).

Tercera parte: Concepciones de los alumnos sobre el estado gaseoso

Se aborda el estudio de las imágenes y analogías que los alumnos utilizan para describir o hablar del aire y de los gases, porque determinan cierto numero de representaciones.

Se estudia la formación de conceptos que definen el estado de un gas. Las magnitudes: masa, cantidad, volumen.

Su adquisición está ligada a los esque. mas de conservación de la sustancia. Estos esquemas han sido estudiados profundamente por J. Piaget para los sólidos y líquidos y aquí para los gases.

Parece que estos esquemas no son adquiridos por todos los alumnos antes de la ensentanza, aunque casi todos los han adquirido para los sólidos y líquidos. Al finalizar $6^{\circ}$ curso, la mayor parte de ellos son capaces de reconocer esta conservación en las transformaciones a temperatura constante $y$ de forma correlativa, evaluar correctamente las cantidades de aire diferenciándolas del volumen. Estos alumnos utilizan de forma preponderante el argumento de la identidad y más raramente el de la reversibilidad.

Cuando se trata de interpretar transformaciones a temperatura variable, $\mathrm{mu}$ chos de los alumnos no reconocen la conservación y no utilizan el argumento de la identidad. Se constata que, como en el caso de la masa, la ensefranza aporta una regresion. Esta es mas im. portante en las «clase no tratadas" que en las "clases tratadas" por nuestro equipo de investigación. En efecto, pa* ra los profesores de estas clases, las diferentes conservaciones han constituido sus objetivos. Las dificultades dadas en la enseffanza provienen siempre del aire caliente «más ligero que el aire frío" "de presión más fuerte», etc.

Aquí se nota una importante asimetría de saberes y de concepciones de los alumnos para el aire caliente y el aire frío.

La adquisición del concepto de presión es difficil. Las imágenes que los alumnos asocian al aire en diferentes estados pueden constituir obstáculos para la adquisición del concepto. Una dificultad proviene también de que los ninos ligan una especie de valor nulo a todo lo que concierne a la atmósfera: 
no ejerce ninguna acción sobre los objetos, su presión es nula. Otra provie. ne de que los alumnos ligan a menudo presión y movimiento, volviendo a encontrar la mayoria de las dificultades que encontraron cuando estudiaron la mecánica.

Las situaciones de cambio de presión por variaciones de temperatura tienen interés en cuanto que la causa de la variación no es otra que el movimiento. Se obtiene así por parte de los alumnos unas interpretaciones que se alejan de aquellas basadas en la transmisión de movimientos, a menudo obtenidas a temperatura constante. Los alumnos atribuyen frecuentemente una dirección privilegiada a las acciones del aire: la vertical ascendente.

Aparece claranente que los alumnos no pueden señalar variaciones de presión teniendo en cuenta todos los parámetros en juego. Siguiendo los puntos sobre los que fijan su observación, llegan a sus errores y a sus contradicciones cuando sacan conclusiones sobre la presión: ya sea porque consideran los diferentes parámetros en juego, ya sea porque intentan señalar las fuerzas y equilibrios.

El reconocimiento de la igualdad de presión es particularmente dificil para ellos ya que por ejemplo, consideran que el aire caliente, en comunicación con la atmósfera, no está a la presión atmosférica.

A medida que avanza la enseñanza, se percibe que los altumnos utilizan cada vez más espontáneamente el parámetro presión. Se observa también que la confusión establecida a menudo entre «presion y cantidad volumetrican (por el sesgo de to que los alumnos llaman el "apretujamiento") es un pesado "handicap» para las experiencias donde la temperatura varía.

De estos resultados se deduce que, respecto a la formación del concepto de temperatura, es interesante estudiar to que son el aire caliente y el aire frio para los alumnos. El aire calentado por una llama, tiene para ellos numerosas propiedades. Por ejemplo, sobre todo antes del aprendizaje, para los alumnos se transforma en o contiene un gas, o $\mathrm{CO}_{2}$. Ninguna representación del mismo tipo es observada para el aire frio.

La consideración de sus desplazamientos hace decir que el aire no es homogéneo: en el fondo de los recipientes calentados se encuentra una zona vacía por ejemplo.

Los fenómenos atribuidos al aire caliente no lo son siempre a los gases calientes. Así los fenómenos de convección en el aire tienen una gran importancia para los alumnos: para ellos se generaliza en todos los casos, mientras que para los físicos, sólo se originan en ciertas condiciones, difíciles de identificar, por otra parte, en las situaciones reales.

Cuarta parte: «La evolución de las representaciones de los alumnos"

Se estudia en diferentes contextos:

* Una observación longitudinal de la clase durante dos años escolares, muestra las concepciones que se desarrollan en una clase, como son tomadas en cuenta por el profesor, cómo los alumnos que tienen concepciones diferentes se las comunican entre ellos y progresan.

Se precisa entonces la evolución real de los alumnos a través del tiempo (tienen ritmos rnuy diferentes) así como las in. teracciones alumno-alumno y alumnosprofesor. Globalmente, parece que la intención del profesor de utener en cuenta las proposiciones de los alumnos» está tanto más actualizada cuanto mejor las conoce y sabe describirlas a medida que avanza el aprendizaje. Parece igualmente que existen interacciones entre alumnos manipulando y trabajando juntos, pero son débiles y a veces quedan en forma potencial si el profesor no las reaiza y amplifica.

* Una «Evaluación autónoma balance) ha sido propuesta igualmente a una veintena de alumnos al final del apren- dizaje, y cinco antes del aprendizaje. Esta actividad donde los alumnos debian resolver un problema puramente experimental muestra los conocimientos y los pasos que los alumnos adoptan espontáneamente para interpretar y organizar experiencias. Aparecen en el análisis de resultados todas las dificultades observadas. Se ve sin embargo la adquisicion importante de los alumnos en cuanto a su enfoque: no hacen ya experiencias "para ver" sino "para probar». Saben tener en cuenta varios sistemas y elegir los momentos de las expertencias en los que tienen que efectuar comparaciones.

- Se ha observado igualmente un pequento grupo de alumnos a los que se les ha propuesto primero una enseñanza sobre los gases a nivel macroscopico. Después de conocer las concepciones de cada uno (esencialmente la estrecha relación entre presión y movimiento), se les ha enseñado un modelo particular cinético de los gases. Se ha podido observar que los alumnos seleccionan elementos del modelo y a partir de él «inventan» otros. Todos han comprendido mejor que el aire atmosfèrico presiona sobre todos los objetos en contacto y lo que significa la frase «el aire caliente es más ligero que el fríon.

\section{Conclusión}

EI conjunto de este trabajo clarifica la evolución seguida por los alumnos en el aprendizaje de las propiedades fís:cas del estado gaseoso, así como los obstáculos y difícultades encontradas. Todo ello es necesario tenerlo presente no sólo para proponer objetivos de conocimiento que sean posibles de alcanzar por alumnos de estas edades, sino también para adoptar estrategias pedagógicas adecuadas. Se proponen modificaciones de experiencias y un cierto número de métodos para su lectura, con el objeto de favorecer la formación de los conceptos de cantidad de materia, volumen, masa y presión en gases.

Traducción de A, Vilches 